\title{
Empowering communities to respond to HIV/AIDS: Ndola Demonstration Project on Maternal and Child Health: Operations research final report
}

Hope Humana

LINKAGES

National Food and Nutrition Commission

Ndola District Health Management Team

Horizons Program

See next page for additional authors

Follow this and additional works at: https://knowledgecommons.popcouncil.org/departments_sbsr-hiv

Part of the Demography, Population, and Ecology Commons, Health Policy Commons, Immune System Diseases Commons, International Public Health Commons, Maternal and Child Health Commons, Medicine and Health Commons, Public Health Education and Promotion Commons, Virus Diseases Commons, and the Women's Health Commons How does access to this work benefit you? Let us know!

\section{Recommended Citation}

Hope Humana, LINKAGES, National Food and Nutrition Commission, Ndola District Health Management Team, Horizons Program, and Zambia Integrated Health Project. 2003. "Empowering communities to respond to HIV/AIDS: Ndola Demonstration Project on Maternal and Child Health: Operations research final report," Horizons Final Report. Washington, DC: Population Council. 


\section{Authors}

Hope Humana, LINKAGES, National Food and Nutrition Commission, Ndola District Health Management Team, Horizons Program, and Zambia Integrated Health Project 


\title{
Herizons N
}

\section{Empowering Communities to Respond to HIV/AIDS}

\author{
Ndola Demonstration Project on \\ Maternal and Child Health: \\ Operations Research Final Report
}
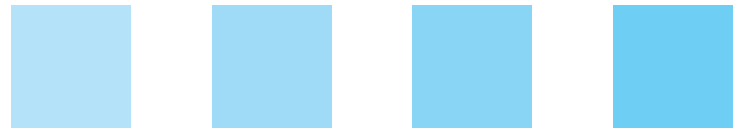

Hope Humana

LINKAGES

National Food and Nutrition Commission Ndola District Health Management Team Horizons Program Zambia Integrated Health Project 


\title{
Empowering Communities to Respond to HIV/AIDS
}

\author{
Ndola Demonstration Project on \\ Maternal and Child Health: \\ Operations Research Final Report
}

Hope Humana

LINKAGES

National Food and Nutrition Commission Ndola District Health Management Team Horizons Program

Zambia Integrated Health Programme
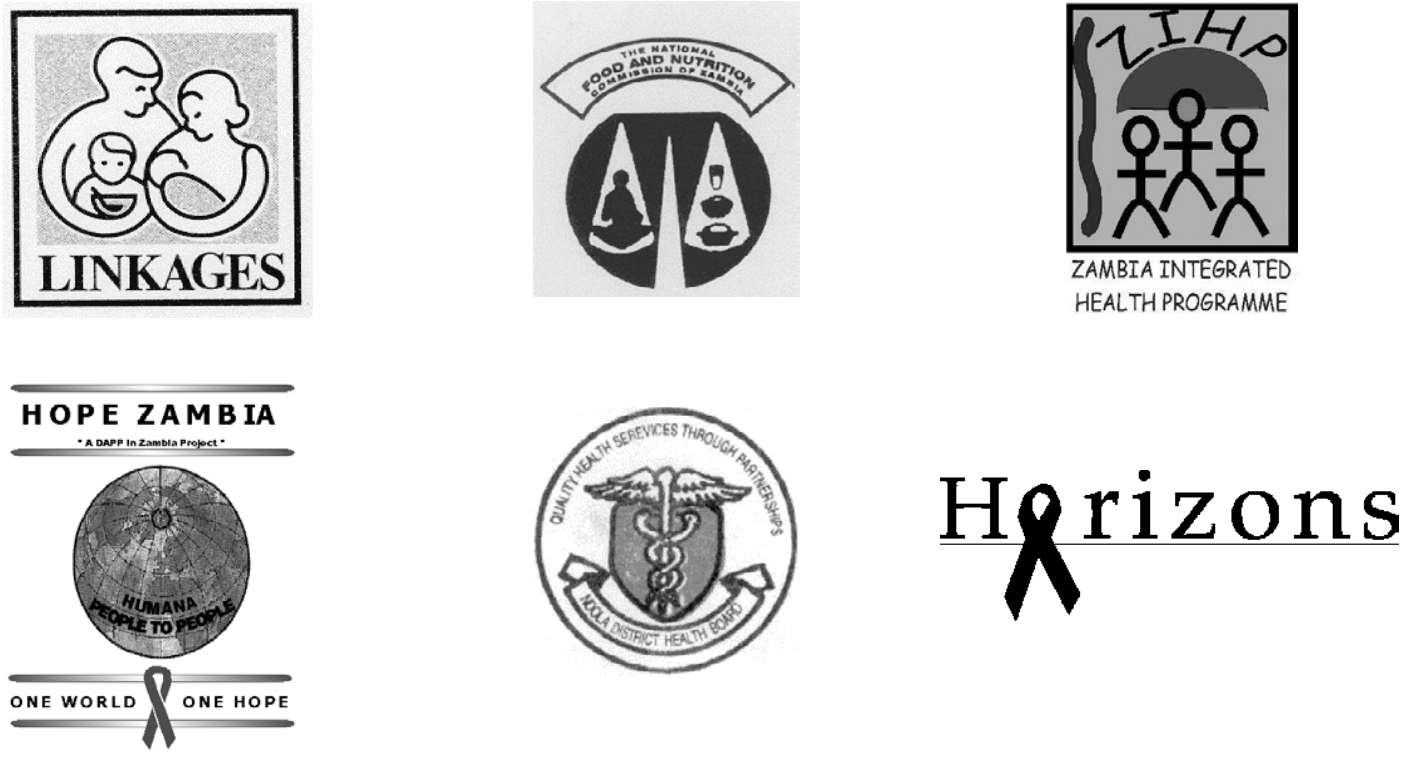
USAID in

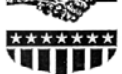
This study was supported by the Horizons Program, which is implemented by the Population Council in collaboration with the International Center for Research on Women, International HIV/AIDS Alliance, Program for Appropriate Technology in Health, Tulane University, Family Health International, and Johns Hopkins University. Horizons is funded by the U.S. Agency for International Development, under the terms of HRN-A-00-97-00012-00. The opinions expressed herein are those of the authors and do not necessarily reflect the views of the U.S. Agency for International Development.

Published in August 2003.

\section{(2) Population Council}

The Population Council is an international, nonprofit, nongovernmental institution that seeks to improve the wellbeing and reproductive health of current and future generations around the world and to help achieve a humane, equitable and sustainable balance between people and resources. The Council conducts biomedical, social science, and public health research and helps build research capacities in developing countries. Established in 1952, the Council is governed by an international board of trustees. Its New York headquarters supports a global network of regional and country offices.

Copyright (C) 2003 The Population Council Inc.

LINKAGES project of the Academy for Educational Development

3039 Makhishi Road, Fair View

P.O. Box 32242

Lusaka, Zambia

tel: +260 1234 11/2

linkages@link.org.zm

www.linkagesproject.org
Horizons Program Population Council

P.O. Box 17643

Nairobi, Kenya

tel: +2542713480

pcnairobi@popcouncil.org

www.popcouncil.org/horizons 


\section{Acknowledgments}

The research component of the Ndola Demonstration Project (NDP) was conducted by Horizons, a USAID-funded global HIV/AIDS operations research project implemented by the Population Council. Horizons' principal investigator for the NDP was Sam Kalibala. Other Horizons team members who contributed to this report (listed alphabetically) include Margaret Dadian, program associate; Julie Denison, program fellow; Scott Geibel, data analyst; Winnie Lubasi, administrative assistant; Norah Omenda, administrative assistant; Naomi Rutenberg, director of research; and Katie Schenk, program associate.

The NDP was implemented by the following partners, who all contributed to the study: LINKAGES provided leadership, guidance, and technical assistance in conceptualizing and developing the research proposal, including the data collection tools. LINKAGES' principal investigator for the NDP was Nomajoni Ntombela, LINKAGES/Zambia resident adviser. Other LINKAGES team members who contributed to this report include Jean Baker, LINKAGES project director; Melissa Barrett, senior monitoring and evaluation associate; Henry Chiyota, program associate; Nadra Franklin, monitoring and evaluation manager; Mary Kroeger, maternal and child health coordinator; Carolyn Kruger, country programs technical manager; Maureen Muzumara, training officer; Tina Nyirenda, training officer; and Jean Tshiula, technical program officer.

The National Food and Nutrition Commission (NFNC) provided overall direction to the study as well as technical assistance on nutrition issues in developing data collection tools. The following NFNC staff also directly participated in all aspects of the study: Mwate Chintu, national coordinator for the Infant Feeding Program (IFP); Priscilla Likwasi, acting executive director; Ward Siamusante, nutritionist; and Ruth Siyandi, nutritionist (seconded to the program).

Ndola District Health Management Team (DHMT) was the main implementer of NDP services and provided overall guidance in the day-to-day management of research activities. DHMT's principal investigator for the NDP was Earnest Muyunda. Other DHMT staff who participated in the NDP included Mwila Lembalemba, manager of planning; Esther Sakala, manager; Ronah Maambo, AIDS/HIV/STD coordinator; Lynette Maambo, community partnerships coordinator; the late Ricky Ndhlovu, information officer; Gideon Phiri, information officer; Angel Sondashi, laboratory technician; and Feiby Moonga, laboratory technician.

The nurses in charge of the clinics in the study area were Beauty Maluti and Godreen Kapotwe (Kabushi); Apronia Musopelo (Kaloko); Anne Banda (Lubuto); Mary Sichula (Masala); Egina Phiri (Mushili); and Agnes Mwafulilwa (Twapia).

The Hope Humana team provided logistics management and participated in various aspects of the study. The team included Millie Bwalya Chikolwa, administrative support; Tresford Chomba, laboratory technician; Wendy Dunnett-Dagg, assistant project manager; Jane Jensen, director; Nila Kaetano, counselor; Chad Kalobwe, community mobilizer; Esnelly Kasongo, counselor; and the late Poso Ngalande, clinical program manager. 
The Zambia Integrated Health Programme (ZIHP) team was a partner throughout various stages of the NDP, from conceptualizing the study to implementing it. Team members included Andrew Mlewa, NGO support coordinator; Bruce Mukwatu, interventions coordinator; Simon Mutonyi, NGO support coordinator; Nosa Orabaton; Elizabeth Serlemitsos, chief of party; Grace Sinyangwe, communication coordinator; Rose Zambezi, community partnerships specialist.

The NDP Operations Research team under DHMT, supported by Horizons and based at Hope Humana, was responsible for the day-to-day operation of the study. This team consisted of the late Hilda Kaunda, study coordinator; Queen Moyowanyambe, research assistant; Stephanie Mpabalwani, assistant study coordinator; Mary Mufaya, research assistant; Elizabeth Nonde, research assistant; Jennifer Ntinda, study secretary and qualitative data entry; Esther Sakala, study coordinator; and Kedrick Sikaona and Lenganje Sikaona, quantitative data entry.

The following consultants provided technical assistance to the operations research team on behalf of Horizons: Cecelia Dadian; Fred Kaona; Rosemary Musonda, Tropical Diseases Research Centre; David Mwandu, Mwengu Social and Health Research; Mary Tuba Siajunza, Mwengu Social and Health Research; and Helen van Houten. Research assistants during the baseline, midterm, and endline surveys are listed in Appendix C. 


\section{Table of Contents}

\section{Abbreviations and Acronyms}

\section{Executive Summary}

Introduction

\section{Background}

Study setting

5

Research question

6

Formative research

6

Study design

6

Intervention

7

Data collection

Data entry and analysis

Profile of respondents

Feasibility of interventions

MTCT knowledge improved but remains incomplete

Breastfeeding practices improved

VCT awareness increased but uptake remains low

Sexual risk reduction needs further emphasis in the community

Communication and disclosure improved but remain limited

Routine $\mathrm{ANC}$ and other $\mathrm{MCH}$ services need additional resources too 
Discussion and Conclusions

Program modifications

References

Additional Reading

\section{Appendixes:}

A. Service Statistics (July 2001) 36

B. Referrals Data 37

C. Research Assistants During the Baseline, Midterm, and 38 Endline Surveys 


\section{Abbreviations and Acronyms}

\begin{tabular}{|c|c|}
\hline $\mathrm{ADH}$ & Arthur Davison Hospital \\
\hline AIDS & acquired immune deficiency syndrome \\
\hline ANC & antenatal care \\
\hline ARV & antiretroviral \\
\hline $\mathrm{CBO}$ & community-based organization \\
\hline $\mathrm{CHW}$ & community health worker \\
\hline DHMT & District Health Management Team \\
\hline DHS & Demographic and Health Survey \\
\hline EBR & exclusive breastfeeding rate \\
\hline FP & family planning \\
\hline $\mathrm{Hb}$ & hemoglobin \\
\hline HIV & human immunodeficiency virus \\
\hline HWs & health workers \\
\hline IF & infant feeding \\
\hline IFC & infant feeding counseling \\
\hline KAP & knowledge, attitudes, and practices \\
\hline $\mathrm{MCH}$ & maternal and child health \\
\hline $\mathrm{MOH}$ & Ministry of Health \\
\hline MTCT & mother-to-child transmission \\
\hline $\mathrm{NCH}$ & Ndola Central Hospital \\
\hline NDP & Ndola Demonstration Project \\
\hline NFNC & National Food and Nutrition Commission \\
\hline NGO & nongovernmental organization \\
\hline NHC & neighborhood health committees \\
\hline PLHA & people/person living with HIV and AIDS \\
\hline PMCT & prevention of mother-to-child transmission \\
\hline PNC & postnatal care \\
\hline STI & sexually transmitted infection \\
\hline TBA & traditional birth attendants \\
\hline TDRC & Tropical Disease Research Centre \\
\hline UN & United Nations \\
\hline USAID & United States Agency for International Development \\
\hline VCT & voluntary counseling and testing \\
\hline WHO & World Health Organization \\
\hline ZIHP & Zambia Integrated Health Programme \\
\hline
\end{tabular}





\section{Executive Summary}

A pre-post intervention study conducted by Horizons, LINKAGES, the National Food and Nutrition Commission of Zambia, Ndola District Health Management Team, Hope Humana, and the Zambia Integrated Health Program demonstrated that the provision of HIV voluntary counseling and testing (VCT) and infant feeding counseling to mothers attending maternal and child health $(\mathrm{MCH})$ clinics are vital components of any mother-to-child transmission (MTCT) reduction strategy, whether or not antiretrovirals (ARVs) are available. These interventions enable mothers to make informed and healthy decisions.

\section{Service Integration Feasible}

The study demonstrated that full integration of VCT and infant feeding counseling (IFC) services into the existing clinic- and community-based MCH services of Ndola was indeed feasible, and local ownership and participation can be achieved through collaborative efforts throughout the project cycle.

\section{MTCT Knowledge Improved But Remains Incomplete}

The possibility of HIV transmission from mother to child was well known in the community even before the intervention. Data from the clinic exit survey indicate that during the intervention mothers became increasingly aware of the possibility of MTCT prevention during breastfeeding and that this message diffused into the wider community through mobilization efforts.

\section{Breastfeeding Practices Improved}

Education stressing the overall benefits of breast milk enabled mothers, including those who were HIV-positive, to evaluate relative risks and benefits and still make the healthy choice of exclusive breastfeeding. Clinic attendees, who were exposed to the enhanced counseling, increasingly adopted the safer practice of exclusive breastfeeding and the riskier practice of mixed feeding declined. Exclusive breastfeeding rates were found to be high at baseline but were confirmed in a separate validation study and were probably the result of breastfeeding promotion programs in Ndola preceding the Ndola Demonstration Project (NDP). The exclusive breastfeeding rate (EBR) among mothers in the community who did not know their HIV status rose from 57 percent at baseline to 70 percent at endline. This trend implies that even as women's understanding of MTCT during breastfeeding improves, good breastfeeding practices are not being eroded. Researchers found no significant differences between the practices of women who knew their HIV status and those who had not been tested; results indicated that all mothers are moving away from mixed feeding toward giving breast milk exclusively for the first six months. Early cessation of breastfeeding and feeding exclusively by replacement remained low. 


\section{VCT Awareness Increased But Uptake Remains Low}

Project implementers overcame supply-side obstacles to meet the logistical requirements of VCT service delivery in this setting, but faced low demand for service uptake, despite increased awareness among mothers in the community ( 56 percent at baseline to 88 percent at endline). Service uptake increased in all clinics but utilization remained low among community mothers (baseline 5 percent, endline 13 percent). Although community members are increasingly aware of the VCT services, they are not using them, possibly due to stigma or a lack of tangible incentives to use the services (e.g., no ARVs or breast milk substitute).

\section{Communication About Risk Reduction Needs More Emphasis in the Community}

Little change in reported HIV risk perception was noted among all groups between baseline and endline. Among all mothers interviewed in the community, condom use at last sex with regular partners was low and remained stable at approximately 13 percent for all survey rounds. Women remain at risk of HIV infection during the perinatal period due to their partners' behavior: Data from the community surveys suggest that while women interviewed in the community surveys report that they are reducing their number of sexual partners, but no significant change was observed among men of reproductive age chosen at random in the same catchment communities. HIV risk reduction communication remains limited although an improvement was observed among mothers interviewed in the community reporting that they had ever discussed HIV risks with anyone, from 55.0 percent at baseline to 64.4 percent at endline.

\section{Routine Antenatal Care Services Need Additional Resources Too}

The intervention aimed to strengthen care during pregnancy, delivery, and the postnatal period by improving clinic infrastructure, providing VCT equipment and supplies, and building capacity of health workers. However, survey data and clinic observations revealed that logistical obstacles hampered some of these goals. Continued investments in both human and physical resources are necessary to provide communities with the staff and infrastructure requirements of routine and enhanced services. MTCT risk reduction programs must strengthen routine $\mathrm{MCH}$ care as an integral component of providing enhanced services.

\section{Care and Support Links Remain Poor}

Community links are essential to promote services and provide follow-up support for mothers after leaving the clinic. Observations indicate that referrals remain limited to major hospitals for medical indications, and not to meet care and support needs at community-based organizations (CBOs). 
Increasing collaboration between clinics and $\mathrm{CBOs}$ is required to provide continuity of care, ongoing information, and support structures for people living with HIV and AIDS (PLHA).

\section{Conclusion}

Data from the Ndola Demonstration Project study have yielded encouraging results from efforts to improve the capacity of mothers to make informed decisions about their own health and the health of their infant. The interventions succeeded in raising awareness about HIV and MTCT and in setting up VCT and IFC services as part of the existing MCH services, as well as good referral links in the community. Regardless of the availability of ARVs, counseling interventions will remain crucial components for the success of any MTCT reduction program. 


\section{Hgrizons}

\section{Introduction}

Preventing mother-to-child transmission (MTCT) of HIV has emerged as a critical issue in subSaharan Africa. While the use of antiretroviral (ARV) drugs for mothers and infants represents an important intervention to significantly reduce the likelihood of MTCT, other simple and possibly cost-effective strategies can be integrated into preexisting maternal and child health (MCH) clinic settings, even in areas where the high costs of ARVs and the lack of a delivery service infrastructure render the drugs unavailable.

The World Health Organization (WHO) and other UN agencies have proposed the following threepronged approach for the prevention of MTCT:

- Primary prevention of HIV among young women.

- Prevention of unintended pregnancy among HIV-infected women.

- Interventions to reduce MTCT among HIV-infected pregnant and lactating women.

In addition, they have proposed a fourth prong, the care and support of women, children, and families infected and affected by HIV/AIDS, which has gained wide acceptance as an important component of MTCT interventions (de Zoysa et al. 2002).

Up to 14 percent of infants born to HIV-positive women contract the virus through breastfeeding. However, refraining from breastfeeding puts infants at risk of morbidity and mortality and may be associated with the stigma of suspected HIV-positive status (LINKAGES 2001). HIV-positive women must evaluate the relative risks and benefits of breastfeeding and replacement feeding regimes. This has particular programmatic significance in high prevalence areas.

International guidelines recommend that all pregnant women have access to VCT and counseling on infant feeding, HIV risk reduction, and family planning (WHO/UNAIDS/UNICEF 1998). The $\mathrm{MCH}$ clinic represents an ideal opportunity to reach women who may not otherwise have access to health services at a time when they may be especially receptive to health information. This counseling remains relevant even in areas where access to ARVs and breast milk substitutes is limited, because women are still entitled to the right of informed choice to make healthy decisions. 


\section{Background}

\section{Study Setting}

In 1998 the Central Board of Health, the Ministry of Health (MOH), the National Food and Nutrition Commission (NFNC), LINKAGES, Zambia Integrated Health Programme (ZIHP), Hope Humana, and Horizons, with the support of USAID, sought an opportunity to pilot the introduction of IFC and VCT at antenatal care (ANC) sites as interventions to reduce MTCT.

In Ndola District, Zambia, in 1999, as in many African communities at this time, neither ARVs nor breast milk substitutes were widely or safely accessible. Strong prior community mobilization efforts against HIV/AIDS made this area an ideal setting for the study. The Ndola Demonstration Project (NDP) provided an opportunity to investigate questions of feasibility and impact of the integration of services for the prevention of MTCT into an existing MCH setting, about which little was known.

The study area comprised 7 adjacent peri-urban settlements with a fairly young and relatively welleducated population of approximately 170,000. In 1999 unemployment was approximately 15 percent, and HIV prevalence among women attending antenatal appointments was 27.2 percent (Musonda et al. 1999). While the majority of households had access to shared piped water, water quality was unsafe due to contamination from damaged pipes. The area was served by six health centers, two local care and support CBOs, and two public hospitals (one pediatric), between which existed potential for a referrals network.

In collaboration with the partners listed above, the Ndola District Health Management Team (DHMT) developed the NDP to test the operational feasibility of an integrated MTCT riskreduction approach linked to ANC. The partners worked together to evaluate the feasibility, acceptability, and implications of improving IFC and introducing VCT into a low-resource ANC/MCH clinic setting, where women did not at the time have access to short-course ARVs such as nevirapine or AZT to reduce vertical transmission. 


\section{Research Question}

\section{How does the integration of VCT and IFC into $\mathrm{MCH}$ and community services, in a low-resource setting without access to ARVs, influence a woman's ability to make and implement informed choices about HIV in pregnancy, maternity care, postpartum care, and infant feeding?}

Specifically, the study aimed to:

- Explore the feasibility of integrating IFC and VCT into enhanced MCH services and a community-based network of neighborhood health committees, NGOs, community-based organizations (CBOs), and other health facilities.

- Examine the effect of these interventions on the mothers' knowledge of MTCT, uptake of VCT, infant-feeding practices, and sexual behavior.

\section{Formative Research}

Formative research conducted by the LINKAGES and SARA projects from December 1998 to February 1999 investigated local feeding options, levels of HIV/MTCT awareness in the community and among health workers, and the standard of clinic facilities in the area (NFNC 1999). From this investigation, it appeared that the only safe and feasible infant feeding option for most mothers in the community was exclusive breastfeeding. Significant knowledge gaps regarding MTCT and infant feeding were identified among community members and health workers. In April 1999 Horizons and other NDP partners conducted an assessment of community resources and capacity (Horizons 2000). This assessment helped to map out the NGOs and CBOs as well as health facilities that could form a referral network relating to NDP. It also helped identify community groups that would deliver the community component of NDP.

\section{Study Design}

The study followed a pre-post intervention design. Baseline surveys were conducted prior to the intervention's introduction in May 2000. Midterm and final data collection rounds were carried out during April to May 2001 and February 2002. At all three data collection points, researchers surveyed community members, clinic clients, and staff regarding their HIV and MTCT knowledge, attitudes, and practices, and observed client-provider interactions. The study also examined the feasibility of delivering the new services under conditions of high staff turnover, erratic supplies, and low staff morale, situations that are frequently found in public health service settings. 


\section{Intervention}

\section{Intervention package}

The formative research findings were used to design the NDP intervention package, which introduced the following initiatives through a strengthened essential ANC care program:

- Counseling on safe and feasible infant feeding options based on principles of informed choice (see below).

- Promoting exclusive breastfeeding for women who are HIV-negative or whose status is unknown.

- Introducing VCT for HIV in MCH and community services.

- Using optimal obstetric procedures during labor and delivery.

- Intensifying community involvement, including the promotion of couple counseling.

Recognizing the need to strengthen the existing clinic infrastructure before introducing the new services, the intervention provided for extensive renovations to the Lubuto clinic and provided VCT supplies and equipment. Existing clinic staff were trained in counseling clients and in processing HIV tests.

The intervention strengthened routine services and introduced VCT and IFC into the MCH/ANC setting. Clinic- and community-based health workers attended intensive training sessions ${ }^{1}$ on HIV counseling and the prevention of MTCT, and additional efforts were made to intensify community involvement, especially of men.

Over the period of the study (May 2000 to March 2002), a total of 12,950 pregnant women sought ANC services as new attendees at the six DHMT clinics (see Table 1 below). These women were all exposed to the health education talks covering topics on HIV, MTCT, and infant feeding issues.

For additional service statistics, see Appendix A.

\footnotetext{
${ }^{1}$ See Table 8 in Results section for further details.
} 
Table 1 New ANC clients April 2000 to March 2002

\begin{tabular}{lccccccc}
\hline & Kabushi & Twapia & Mushili & Lubuto & Kaloko & Masala & Total \\
\hline Apr-Dec 2000 & 747 & 797 & 770 & 699 & 566 & 1,271 & 4,850 \\
Jan-Dec 2001 & 1,037 & 1,083 & 933 & 1,352 & 653 & 1,731 & 6,789 \\
Jan-Mar 2002 & 229 & 326 & 200 & 421 & 171 & 478 & 1,825 \\
Total & 2,013 & 2,206 & 1,903 & 2,472 & 1,390 & 3,480 & 13,464
\end{tabular}

\section{Community component}

Following the assessment of the local community-based organizations, stakeholders took steps to establish a referrals network on HIV and reproductive health issues, including the development of a referral directory, referral slips, and a system of regular meetings between partners. Stakeholders identified a variety of community groups, including neighborhood health committees (NHCs), home-based care groups, mother support volunteers, positive living groups, traditional birth attendants (TBAs), child health promoters, and community-based distributors. The intervention strengthened these groups mainly by providing training in HIV/AIDS, MTCT prevention, and VCT. By February 2001 approximately 160 community health workers from these groups and CBOs had received this training. In addition, a group of these community health volunteers were trained as HIV and IF counselors to provide pre- and post-test HIV and nutritional counseling to mothers and others in the communities.

The community groups collaborated with NDP in several ways including educating the community about HIV, MTCT, and VCT; providing support to mothers after they returned home following delivery; educating men about their role in MTCT prevention and other reproductive health issues; facilitating activities with male community health workers (CHWs) acting as role models for other men; and providing health education and individual counseling at growth monitoring posts.

\section{Infant feeding counseling}

The most innovative aspect of the NDP is the placement of IFC as the centerpiece of the MTCT intervention. IFC is provided to women at various stages throughout the health care system. Infant feeding is among the ANC topics routinely covered by group talks given to mothers in the ANC waiting hall. Infant feeding is also discussed as part of pre- and post-test counseling for mothers choosing to receive VCT (see below). After delivery, mothers receive further infant feeding support at the time of discharge from the health center, at growth monitoring visits at the clinic, and at outreach posts. Women could also visit a clinic or community-based counselor for one-on-one infant feeding counseling either during her pregnancy or following the birth of her child. Systems of routine data collection have been established to record at which of these opportunities women have been counseled on infant feeding. 
Women choosing to receive VCT first attend a confidential pre-test counseling session with a certified counselor. If a woman decides to go ahead with the HIV test, her blood sample is collected on-site and sent to the laboratory for testing. A counselor confidentially discloses her test results when she returns after at least one week.

The pre-test counseling and post-test counseling both included a discussion of infant feeding options. The content of the infant feeding counseling (IFC) was dependent on the client's decision whether or not to go ahead with HIV testing, and the results she receives:

- A woman receiving a negative HIV test result is advised by the counselor to exclusively breastfeed, in order to ensure that her infant receives the full nutritional and health benefits of breast milk.

- A woman receiving a positive HIV test result receives information on the relative risks and benefits of exclusive breastfeeding and replacement feeding, including socioeconomic and household factors, and is discouraged from mixed feeding.

- A woman choosing not to be tested for HIV receives exactly the same advice as if she had tested negative: exclusive breastfeeding.

HIV-negative women and women who did not know their HIV status were counseled to breastfeed their infants exclusively for the first six months, in accordance with international infant feeding guidelines based on balancing the risks of HIV transmission from breast milk and the risks of inadequate nutrition or unhygienic replacement feed preparation. Regardless of the mother's HIV status, mixed feeding is inadvisable during the first six months for health reasons related to nutritional status and child survival. Counselors advised HIV-positive mothers that mixed feeding could have the added negative effect of increasing MTCT risks.

During the period May 2000 to March 2002, 1,442 ANC clients were tested for HIV (for complete service statistics see Appendix A).

\section{Data Collection}

\section{Quantitative surveys}

Questionnaires were developed to measure changes in knowledge, attitudes, and practices about $\mathrm{MCH}$, infant feeding, MTCT, VCT, and general HIV issues among mothers identified in clinics and communities, community members, and health workers.

Table 2 summarizes the sample sizes for each of the different data collection methods used at baseline and midterm. Denominator values have not been given in the text that follows unless they differ greatly from the sample sizes indicated below due to missing data or if the data reflect a subsample (e.g., "clinic mothers tested for HIV"). 
Table 2 Sample sizes by data collection method

\begin{tabular}{|c|c|c|c|c|c|c|}
\hline & \multicolumn{2}{|c|}{ Baseline } & \multicolumn{2}{|c|}{ Midterm } & \multicolumn{2}{|c|}{ Endline } \\
\hline & Female & Male & Female & Male & Female & Male \\
\hline \multicolumn{7}{|l|}{ Clinic survey } \\
\hline Mothers $(A+B)$ & 460 & & 187 & & 241 & \\
\hline $\begin{array}{l}\text { Mothers of infants less than } 6 \\
\text { mos. (A) }\end{array}$ & 371 & - & 111 & - & 189 & - \\
\hline Mothers of infants 6-12 mos. (B) & 89 & - & 74 & - & 52 & - \\
\hline Pregnant women (C) & 125 & - & 125 & - & 138 & - \\
\hline Total $(A+B+C)$ & 585 & & 310 & & 379 & \\
\hline \multicolumn{7}{|l|}{ Community survey } \\
\hline General population adults (D) & 385 & 251 & 441 & 232 & 396 & 231 \\
\hline $\begin{array}{l}\text { Mothers of infants less than } 6 \\
\text { mos. }(E)\end{array}$ & 209 & - & 319 & - & 354 & - \\
\hline Total $(D+E)$ & \multicolumn{2}{|c|}{845} & \multicolumn{2}{|c|}{992} & \multicolumn{2}{|c|}{981} \\
\hline \multicolumn{7}{|l|}{$\begin{array}{l}\text { Other denominators derived from } \\
\text { community and clinic surveys } \\
\text { combined }\end{array}$} \\
\hline $\begin{array}{l}\text { All mothers of infants } 0-12 \text { mos. } \\
(A+B+E)\end{array}$ & 669 & & 504 & & 595 & \\
\hline $\begin{array}{l}\text { All mothers of infants less than } \\
6 \text { mos. }(A+E)\end{array}$ & 580 & & 430 & & 543 & \\
\hline $\begin{array}{l}\text { All mothers and pregnant women } \\
(A+B+C+E)\end{array}$ & 794 & & 629 & & 733 & \\
\hline $\begin{array}{l}\text { All survey respondents } \\
(A+B+C+D+E)\end{array}$ & \multicolumn{2}{|c|}{1,430} & \multicolumn{2}{|c|}{1,302} & \multicolumn{2}{|c|}{1,360} \\
\hline Health workers survey & \multicolumn{2}{|c|}{62} & \multicolumn{2}{|c|}{65} & \multicolumn{2}{|c|}{79} \\
\hline $\begin{array}{l}\text { Client-health worker interactions } \\
\text { observed }\end{array}$ & \multicolumn{2}{|c|}{469} & \multicolumn{2}{|c|}{392} & \multicolumn{2}{|c|}{417} \\
\hline
\end{tabular}


Clinic survey: Pregnant women and mothers of infants less than 12 months old received a questionnaire, administered as an exit interview to every fourth woman using ANC or the infant immunization services at the intervention clinics during a single week. A total of 585 women were interviewed at baseline, 310 at midterm, and 379 at endline. The breakdown of sample sizes according to whether respondents were pregnant or the mother of an infant less than six or 12 months old is listed in Table 2.

Community mothers survey: During the general household survey at baseline (see below), 209 mothers of infants less than six months old were recruited from the community. At baseline, a "snowballing" method was used whereby respondents were asked to identify other mothers of infants less than six months old within the neighborhood. At midterm and endline, mothers of infants less than six months old were selected for interviews by sampling from a census undertaken in the project areas. This more rigorous sampling methodology was adopted to improve the validity and increase the sample size.

General community survey: Community members were surveyed at baseline, midterm, and endline on their knowledge, attitudes, and behavior regarding HIV and infant feeding. Households were selected at random from the statistical enumeration areas of the census and weighted according to catchment area. In accordance with standard DHS and census definitions of residency, men and women (age 15 years or older) who had spent the previous night in the household were interviewed.

Health workers survey: All clinical and counseling staff at the DHMT clinics and the collaborating community-based organizations were interviewed.

Interaction observations: Client-health worker interactions were observed at baseline, midterm, and endline to assess change in the content and quality of service provided. Counselors and clinicians were trained to observe and grade health workers according to a checklist developed for IFC, ANC, labor, postnatal care (PNC), immunization and growth monitoring, sick-child visits, family planning, and VCT services provided. Table 3 indicates the number of interactions that were observed by type of service. 
Table 3 Number of client-health worker interactions observed by type of service

\begin{tabular}{lccc}
\hline & $\begin{array}{c}\text { Baseline } \\
\mathbf{n}=\mathbf{4 6 9}\end{array}$ & $\begin{array}{c}\text { Midterm } \\
\mathbf{n = 3 9 2}\end{array}$ & $\begin{array}{c}\text { Endline } \\
\mathbf{n = 4 1 7}\end{array}$ \\
\hline Antenatal care & 56 & 41 & 49 \\
Labor & 42 & 20 & 29 \\
Postnatal care & 48 & 40 & 49 \\
Immunization and growth monitoring & 46 & & \\
Infant feeding counseling & 54 & 41 & 48 \\
Sick-child visit & 51 & 30 & 42 \\
Family planning & 46 & 42 & 48 \\
Voluntary counseling and testing & & 47 & 48 \\
General counseling & 50 & & 24
\end{tabular}

\section{Qualitative cohort}

In addition to the surveys and observations, a small cohort of 57 mother-baby pairs was recruited for intensive follow-up, to document the experiences of women as they make and implement decisions regarding HIV, pregnancy, and infant feeding. Interviews took place after the start of the intervention, between August 2000 and May 2002. As shown in Table 4 below, the cohort included HIV-negative and -positive mothers and guardians.

Researchers intended to conduct interviews with mothers during counseling sessions, following exposure to the intervention, at approximately quarterly intervals until 12 months after delivery. Table 5 below indicates that loss to follow-up was evident by the second interview. Illustrative quotes from members of the qualitative cohort have been included throughout this report. 
Table 4 Composition of qualitative cohort

\begin{tabular}{lc}
\hline & Number of Respondents \\
\hline HIV-negative mothers breastfeeding & 14 \\
HIV-positive mothers breastfeeding & 14 \\
Guardians with orphans on alternate feeds & 12 \\
Untested mothers breastfeeding & 16 \\
Tested mother breastfeeding, status undisclosed & 1 \\
Total & $\mathbf{5 7}$
\end{tabular}

Table 5 Qualitative sample size

Number of Respondents

\begin{tabular}{lc}
\hline First interview & $57^{\mathrm{a}}$ \\
Second interview & 20 \\
Third interview & 9 \\
Fourth interview & 3 \\
a 3 prenatal, 54 postnatal &
\end{tabular}

\section{Data Entry and Analysis}

Quantitative data were double-entered by two data entry clerks using Epi-Info software. Data were imported into SPSS for analysis. Unless otherwise indicated, Pearson's chi-square test of independence was used to determine significance. Results are considered statistically significant at or below the 0.05 level. Where significance of a comparison between the two rounds of data is not indicated, this is because the questions differed between the two survey rounds.

Qualitative data were managed using NUD*IST software, followed by discussions in small groups with providers and study staff to extract main themes. 


\section{Hgrizons}

\section{Results}

\section{Profile of Respondents}

\section{Clinic attendees and community members}

The six clinics participating in the NDP were Kabushi, Kaloko, Lubuto, Masala, Mushili, and Twapia, located in adjacent peri-urban low-cost residential areas. Labor and delivery services are provided at Lubuto, Masala, and Twapia; however, renovation work at the Lubuto clinic during the data collection period limited the recruitment of respondents from this clinic at baseline and prevented recruitment entirely at midterm.

Each clinic provides $\mathrm{ANC}, \mathrm{MCH}$, and curative services to local residents of that estate, but catchment areas may overlap. The community survey covered these six communities plus an additional area, Kantolomba, whose residents also seek health care from the Lubuto health center. The respondents for the community surveys were sampled proportionally to the size of the population of each community.

The community survey of adults age 15 and older revealed that the six Ndola communities surveyed have a fairly young population, with 51 to 66 percent of the male and female survey respondents between 15 and 29 years old. The Ndola community is relatively well educated: At least 90 percent of all survey respondents had attended school at some stage, and among the mothers interviewed in the community the mean highest school grade completed was seventh grade. The mothers interviewed in the community and the clinic surveys were young, with a mean age of approximately 24 to 25 years. The men surveyed tended to be older and have a higher rate of school attendance and completion than the female survey respondents.

Most mothers and pregnant women (at least 80 percent) interviewed at the clinic were married, but only about half the men and women interviewed in the community survey were married. Few of the mothers in the community and clinic surveys were widowed ( 0.8 to 5 percent), with no pregnant woman reporting being widowed at baseline, only two at midterm, and none at endline.

The unemployment rate in Ndola is high. About 15 to 25 percent of men and women surveyed in the community were unemployed. Only about 20 percent of men and 1 to 5 percent of women were in regular full time employment; 25 to 32 percent of men and 11 to 18 percent of women were selfemployed. Most pregnant women (69 to 80 percent) and women with small children (63 to 79 percent) were full-time housewives. The community samples included about 20 percent of males and 10 percent of females who were still in school.

The localities vary in the quality of housing and access to water and sanitation. Dwellings in Kabushi, Lubuto, Masala, and Mushili are made predominantly of brick and cement with asbestos roofs. Many Kaloko and Twapia residents live in poorer quality housing, with roofing usually of 
asbestos or tin. Few households in Twapia, Kaloko, and Kantolomba, which is the poorest of the compounds, have individual water and toilet facilities.

Table 6 shows the types of water supply in the homes of clinic and community survey respondents from each compound. Although most homes in Ndola district have access to piped water, access varies considerably between settlements. Some of the shared water pipes may be in bad condition or located close to shared pit latrines. Access to clean water is essential for mothers choosing to replace or supplement breast milk with formula feed, so service providers must question and take into account the water source of the household when advising mothers about their infant feeding options. Infant feeding formula mixed with contaminated water exposes infants to the risks of contracting diarrhea and other water-borne illnesses.

Table 6 Community and clinic respondents' main source of drinking water by settlement at midterm

\begin{tabular}{|c|c|c|c|c|}
\hline & $\begin{array}{c}\text { Piped waterl } \\
\text { home } \\
\text { n (\%) }\end{array}$ & $\begin{array}{c}\text { Piped water/ } \\
\text { shared } \\
\text { n (\%) }\end{array}$ & $\begin{array}{c}\text { Water from } \\
\text { open well } \\
\text { n (\%) }\end{array}$ & $\begin{array}{c}\text { Water from } \\
\text { covered well } \\
\text { or borehole } \\
\text { n (\%) }\end{array}$ \\
\hline Lubuto $(n=194)$ & $178(91.8)$ & $16(8.2)$ & & \\
\hline Masala $(n=247)$ & $147(59.5)$ & $98(39.9)$ & & $2(0.8)$ \\
\hline Twapia $(n=132)$ & $18(13.6)$ & 87 (65.9) & $13(9.8)$ & $14(10.6)$ \\
\hline Kabushi $(n=195)$ & $107(54.9)$ & $87(44.6)$ & & $1(0.5)$ \\
\hline Mushili $(n=370)$ & $223(60.3)$ & $138(37.3)$ & & $9(2.4)$ \\
\hline Kaloko $(n=79)$ & $5(6.3)$ & $74(93.7)$ & & \\
\hline Kantolomba $(n=56)$ & $2(3.6)$ & $54(96.4)$ & & \\
\hline Other $(n=29)$ & $12(41.4)$ & $6(20.7)$ & $6(20.7)$ & $5(17.2)$ \\
\hline Total $(n=1,302)$ & $692(53.1)$ & $560(43.0)$ & $19(1.5)$ & $31(2.4)$ \\
\hline
\end{tabular}

\section{Health workers}

Sixty-two health workers were interviewed at baseline, 65 at midterm, and 79 at endline from the six DHMT clinics and the collaborating NGOs (Table 7). Most were enrolled midwives; other health professionals interviewed included clinical officers and registered nurses. 


\section{Hgrizons}

Table 8 shows that, at baseline, less than one fourth had received previous training in the selected topics of the intervention. According to the midterm and endline results, the greatest increase in reported training occurred for HIV counseling (from 18 at baseline, to 52 at midterm, to 32 percent at endline) and STIs (from 16, to 28, to 32 percent). Reported training in lactation management and family planning did not appear to change significantly. Specific topic recall data may be lower than anticipated due to the fact that providers may associate the term "lactation management" with a specific course conducted by the MOH.

Table 7 Qualifications of health worker respondents

\begin{tabular}{lccc}
\hline Staff member & Baseline & Midterm & Endline \\
\hline Enrolled midwives & 47 & 45 & 50 \\
Clinical officers & 7 & 10 & 14 \\
Registered nurses & 5 & 5 & 9 \\
Other & 3 & 5 & 6 \\
Total & $\mathbf{6 2}$ & $\mathbf{6 5}$ & $\mathbf{7 9}$
\end{tabular}

Table 8 Reported training of health worker respondents

\begin{tabular}{lccc}
\hline Have you received training in...? & $\begin{array}{c}\text { Baseline } \\
\mathbf{n = 6 2} \\
\mathbf{n}(\%)\end{array}$ & $\begin{array}{c}\text { Midterm } \\
\mathbf{n = 6 5} \\
\mathbf{n}(\%)\end{array}$ & $\begin{array}{c}\text { Endline } \\
\mathbf{n}=\mathbf{7 9} \\
\mathbf{n}(\%)\end{array}$ \\
\hline HIV counseling & $11(18)$ & $34(52)$ & $25(32)$ \\
FP & $14(23)$ & $18(28)$ & $24(30)$ \\
STIs & $10(16)$ & $18(28)$ & $25(32)$ \\
Lactation management & $6(10)$ & $7(11)$ & $9(11)$
\end{tabular}

\section{Feasibility of Interventions}

The study demonstrated that full integration of VCT and IFC services into the existing clinic- and community-based MCH services of Ndola was indeed feasible. Local ownership and participation was achieved, with DHMT and clinic staff playing key roles in all stages of the project, from formative research and planning meetings, through intervention and research development and implementation. 
By enabling mothers to learn their HIV status, the NDP has given health care providers the opportunity to increase the volume of services they deliver to known HIV-positive women and thus improve the quality of care they provide. After the introduction of the intervention, more health workers (HWs) reported that they had provided care to an HIV-positive pregnant woman (48 percent at baseline to 61 percent at endline) although this was not statistically significant. The proportion of HWs that said they felt technically competent to provide IFC was relatively high at baseline (73 percent), and remained high after the intervention (71 percent at endline).

Observations of VCT sessions showed that discussion of MTCT during pre-test counseling increased from 14 of 26 sessions (53.8 percent) observed at baseline, to 15 of 16 (93.8 percent) sessions observed at endline ( $p<0.05$, Fisher's exact test). In post-test VCT sessions, discussion of infant feeding choices increased from four of ten sessions at baseline, five of five sessions at midterm, to two of three sessions at endline. Evidence from observation of client-provider interactions indicates that IFC has been increasingly integrated into VCT sessions, although the small sample size (due to logistical difficulties) makes it difficult to assess significance.

Study aims included exploration of the feasibility of IFC and VCT integration into a communitybased network of neighborhood health committees, NGOs, CBOs, and other health facilities. CHWs from the catchment communities were very involved with the intervention, as participants in training and local dissemination activities, leaders of community training sessions, and field guides. In addition, local CBOs played vital collaborative roles in facilitating community ownership of the intervention study, making it possible to successfully incorporate rigorous research methods into a community-based project. Hope Humana provided staff and training for counseling and logistical support to the research team. Stakeholders developed an active referrals network between local organizations linked to NDP, holding regular meetings and making referrals (see Figure 4).

\section{MTCT Knowledge Improved But Remains Incomplete}

HIV transmission from mother to child was well known in the community even before the intervention. Figure 1 shows that awareness of all three transmission modes among mothers in the community increased after the introduction of the intervention, and remained high.

"If the child did not contract through pregnancy, he can contract through breastfeeding".

HIV-negative mother, 39 years, first interview, ten days postpartum 


\section{Figure 1 Community mothers' knowledge of MTCT modes of transmission}

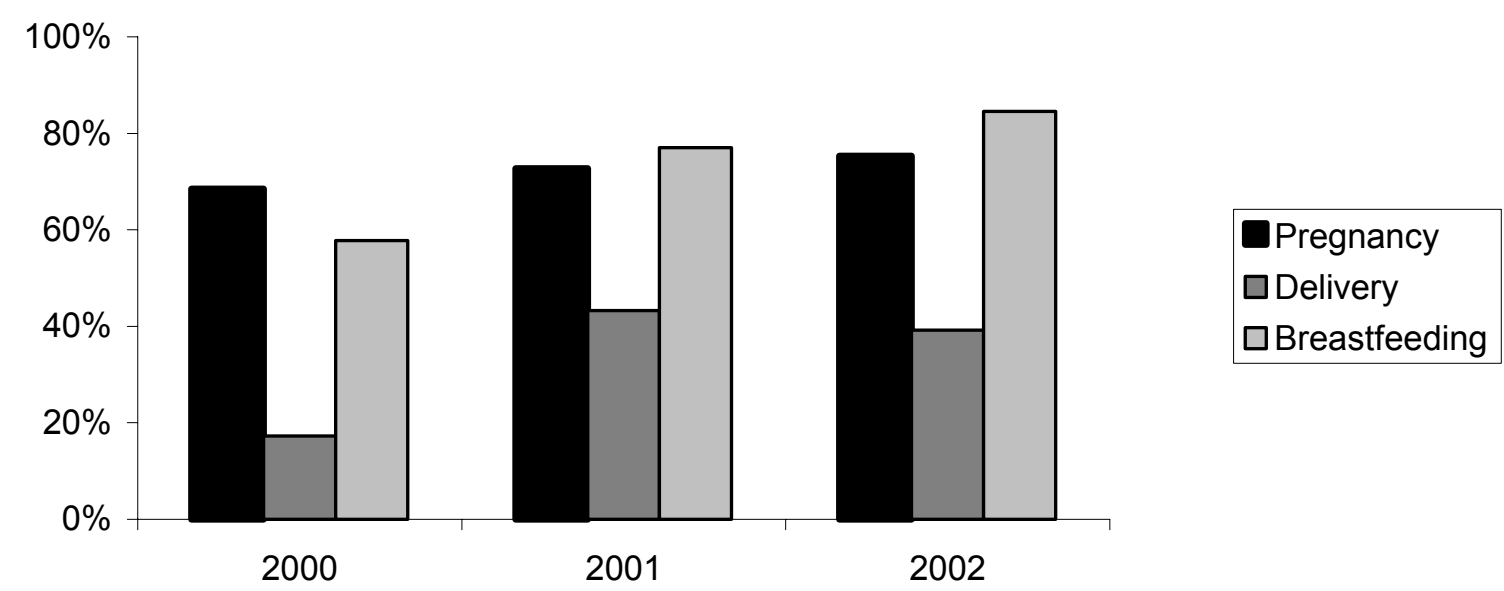

Data from the clinic surveys indicate that more mothers became aware of the possibility of MTCT prevention during breastfeeding. At baseline, 31.8 percent of respondents indicated that they believed that nothing could be done to prevent MTCT during breastfeeding, but by endline, this had declined dramatically to 3.9 percent. Data from the community surveys (shown in Figure 2 below) indicate that by midterm, this intervention message had already diffused into the community to reach both mothers of infants aged under six months and male community members, indicating the effects of community mobilization efforts and the power of word of mouth. 


\section{Figure 2 Community members who believe that "nothing can be done" to prevent MTCT during breastfeeding}

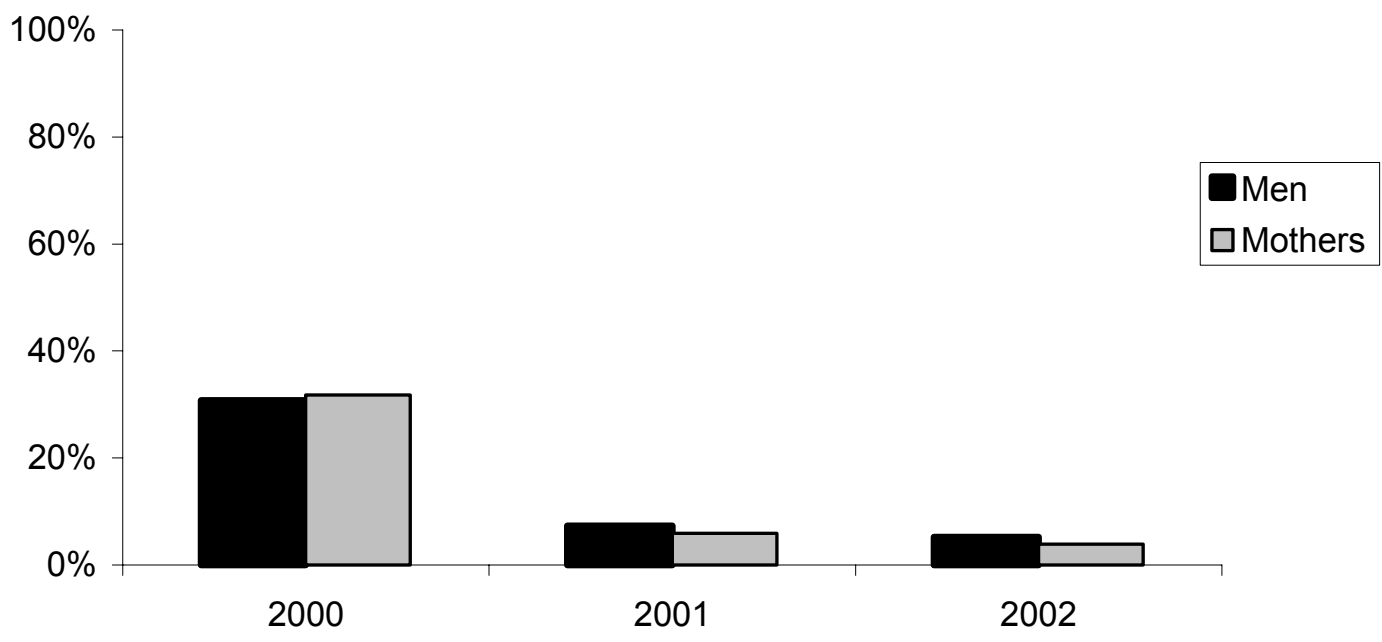

Community members' ability to suggest prevention methods for all transmission modes improved significantly. In particular, abstinence and condoms during pregnancy and labor management were the most widely known methods. For example, during the baseline ${ }^{2}$ survey asking mothers in the community to suggest methods of MTCT reduction during pregnancy, condoms were mentioned by approximately 8 percent and abstinence by approximately 11 percent. By endline, awareness of these methods had increased to 29.4 percent and 38.5 percent, respectively.

"I was told that when having sex, my husband should be wearing a condom because minus a condom, the HIV virus can enter and cause problems to the baby inside the womb who can become sick also."

HIV-positive, 29 years, first interview, two months postpartum

"When in labor I should explain that me, I am like this (HIV'positive), so make sure when cutting the cord they don't mix the baby's blood with mother's"

HIV-positive mother, 22 years, second interview, eight months postpartum

At baseline, no mothers in the community mentioned exclusive breastfeeding as a method to avoid MTCT during breastfeeding, but 7.6 percent suggested this method at endline $(p<0.05)$. Although this change was significant, awareness remains low, calling for further education efforts among mothers to recognize exclusive breastfeeding as the healthiest feeding option for all infants, with lower MTCT risks than mixed feeding. Indeed, this concept appears not to have been well

\footnotetext{
${ }^{2}$ Baseline data are approximate, since questions may have been asked as both single and multiple response by interviewers.
} 


\section{Hgrizons}

understood by health workers either: Although the proportion of providers identifying exclusive breastfeeding as one of the ways to reduce MTCT during breastfeeding increased from the baseline level of 17.7 percent, it remained low, reaching only 29.1 percent at endline.

\section{Breastfeeding Practices Improved}

In order to ensure optimal delivery practices and maximum feeding support at the crucial period immediately following delivery, NDP providers encouraged mothers to give birth at health facilities. As the study progressed, the percentage of community women who reported giving birth in a health center covered by the NDP increased from 48 percent at baseline to 59 percent at endline. Initiating breastfeeding within the first hour after birth, when the baby's suckling reflexes are very strong, has the added advantage of reducing postpartum bleeding. The number of mothers interviewed in the community who initiated early breastfeeding increased from an estimate of 55 percent at baseline to 87 percent at endline.

Women interviewed while exiting clinic services increasingly adopted the safer practice of exclusive breastfeeding and the riskier practice of mixed feeding declined. The EBR among clinic attendees who did not know their HIV status rose from 71 percent at baseline to 84 percent at endline. This is a particularly important positive outcome because it shows that increasing knowledge of MTCT through breast milk did not cause a "spillover" of replacement feeding among women of unknown HIV status. This trend implies that even as women's understanding that HIV can be passed from a mother to her child through breastfeeding improves, good breastfeeding practices are not being eroded. Indeed, the mothers were very well aware that breast milk is the best food for the baby.

"[Breast milk] has vitamins, various nutrients, like an injection, he will grow into a strong baby... There is everything that the baby requires."

Untested mother, 23 years, second interview, 15 days postpartum
Table 9 indicates that the community survey found a surprisingly high baseline EBR among women who did not know their HIV status: 57 percent, compared to the 1996 DHS estimate of 19 percent. ${ }^{3}$ By midterm, the EBR among this group had increased to 76 percent, and at endline 70 percent of these women were breastfeeding exclusively.

\footnotetext{
${ }^{3}$ In order to verify the surprisingly high baseline EBR, researchers undertook validation exercises at endline. A separate community survey was performed using non-health care worker interviewers, and a control community in an area of Ndola not directly affected by the NDP intervention was interviewed to test for interviewer bias. These activities provided results consistent with the earlier findings. The high baseline EBR may have been the result of earlier breastfeeding promotion activities in the area, and may also be associated with poverty levels.
} 
Interpreting infant feeding practices of women who know their HIV status is more difficult. To honor confidentiality, interviewers did not ask for HIV status, so it is impossible to link a mother's HIV status to infant feeding practices. Advice given by HWs depends on whether mothers have voluntarily disclosed HIV status. Although sample size is small for women who know their HIV status, results show that these mothers too are moving away from the riskier practice of mixed feeding (breast milk along with other liquids and solids) toward the recommended practice of giving breast milk exclusively for the first six months. Early cessation of breastfeeding after six months of exclusive breastfeeding and exclusive replacement feeding (infant formula, powdered whole milk, liquid milk from the shops, or fresh cow's milk) barely appeared to be practiced at all, implying exclusive replacement feeding was simply not feasible for women, as the formative research had suggested. Very few women in the community sample were feeding exclusively by replacement.

\section{Table 9 Current feeding practices among community mothers of infants less} than 6 months old

\begin{tabular}{|c|c|c|c|c|c|c|c|c|c|}
\hline $\begin{array}{l}\text { Community } \\
\text { mothers of } \\
\text { infants less } \\
\text { than } 6 \text { mos. } \\
\text { old }\end{array}$ & $\begin{array}{l}\text { Know } \\
\text { HIV } \\
\text { status } \\
n=10\end{array}$ & $\begin{array}{l}\text { Baseline } \\
\text { Do not } \\
\text { know } \\
\text { HIV } \\
\text { status } \\
n=198\end{array}$ & $\begin{array}{l}\text { Total } \\
\mathrm{n}=\mathbf{2 0 8}\end{array}$ & $\begin{array}{l}\text { Know } \\
\text { HIV } \\
\text { status } \\
n=40\end{array}$ & $\begin{array}{l}\text { Midterm } \\
\text { Do not } \\
\text { know } \\
\text { HIV } \\
\text { status } \\
\mathrm{n}=279\end{array}$ & $\begin{array}{c}\text { Total } \\
\mathrm{n}=319\end{array}$ & $\begin{array}{l}\text { Know } \\
\text { HIV } \\
\text { status } \\
n=40\end{array}$ & $\begin{array}{l}\text { Endline } \\
\text { Do not } \\
\text { know } \\
\text { HIV } \\
\text { status } \\
n=314\end{array}$ & $\begin{array}{c}\text { Total } \\
\mathrm{n}=\mathbf{3 5 4}\end{array}$ \\
\hline $\begin{array}{l}\text { Exclusive } \\
\text { breastfeeding }\end{array}$ & $\begin{array}{c}7 \\
(70 \%)\end{array}$ & $\begin{array}{c}112 \\
(56.6 \%)\end{array}$ & $\begin{array}{c}119 \\
(57.2 \%)\end{array}$ & $\begin{array}{c}28 \\
(70.0 \%)\end{array}$ & $\begin{array}{c}213 \\
(76.3 \%)\end{array}$ & $\begin{array}{c}241 \\
(75.5 \%)\end{array}$ & $\begin{array}{c}26 \\
(65.0 \%)\end{array}$ & $\begin{array}{c}221 \\
(70.4 \%)\end{array}$ & $\begin{array}{c}247 \\
(69.8 \%)\end{array}$ \\
\hline $\begin{array}{l}\text { Mixed } \\
\text { feeding }^{a}\end{array}$ & $\begin{array}{c}3 \\
(30 \%)\end{array}$ & $\begin{array}{c}85 \\
(42.9 \%)\end{array}$ & $\begin{array}{c}88 \\
(42.3 \%)\end{array}$ & $\begin{array}{c}11 \\
(27.5 \%)\end{array}$ & $\begin{array}{c}65 \\
(23.3 \%)\end{array}$ & $\begin{array}{c}76 \\
(23.8 \%)\end{array}$ & $\begin{array}{c}14 \\
(35.0 \%)\end{array}$ & $\begin{array}{c}93 \\
(29.6 \%)\end{array}$ & $\begin{array}{c}107 \\
(30.2 \%)\end{array}$ \\
\hline $\begin{array}{l}\text { Exclusive } \\
\text { replacement } \\
\text { feeding/milk } \\
\text { only }\end{array}$ & $\begin{array}{c}0 \\
(0 \%)\end{array}$ & $\begin{array}{c}0 \\
(0 \%)\end{array}$ & $\begin{array}{c}0 \\
(0 \%)\end{array}$ & $\begin{array}{c}0 \\
(0 \%)\end{array}$ & $\begin{array}{c}0 \\
(0 \%)\end{array}$ & $\begin{array}{c}0 \\
(0 \%)\end{array}$ & $\begin{array}{c}0 \\
(0 \%)\end{array}$ & $\begin{array}{c}0 \\
(0 \%)\end{array}$ & $\begin{array}{c}0 \\
(0 \%)\end{array}$ \\
\hline $\begin{array}{l}\text { Exclusive } \\
\text { replacement } \\
\text { feeding/other } \\
\text { feeds }\end{array}$ & $\begin{array}{c}0 \\
(0 \%)\end{array}$ & $\begin{array}{c}1 \\
(0.5 \%)\end{array}$ & $\begin{array}{c}1 \\
(0.5 \%)\end{array}$ & $\begin{array}{c}1 \\
(2.5 \%)\end{array}$ & $\begin{array}{c}1 \\
(0.4 \%)\end{array}$ & $\begin{array}{c}2 \\
(0.6 \%)\end{array}$ & $\begin{array}{c}0 \\
(0 \%)\end{array}$ & $\begin{array}{c}0 \\
(0 \%)\end{array}$ & $\begin{array}{c}0 \\
(0 \%)\end{array}$ \\
\hline p-value & \multicolumn{2}{|c|}{$p=0.317^{d}$} & \multicolumn{4}{|c|}{$p=0.509^{e}$} & \multicolumn{3}{|c|}{$p=0.485^{e}$} \\
\hline
\end{tabular}

**NOTE: Statistical tests based on exclusive breastfeeding and mixed feeding data; not exclusive replacement feeding.

${ }^{a}$ Breast milk along with other liquids and/or solids.

${ }^{\mathrm{b}}$ No breast milk given; replaced with infant formula, powdered milk for adults, liquid milk from the shops, or fresh cow's milk.

${ }^{\mathrm{C}}$ No breast milk given; replaced with other milks and/or feeds.

${ }^{d}$ One-sided result using Fisher's exact test on cross tabulation for baseline survey; two-sided test result was $p=0.552$.

${ }^{\mathrm{e}}$ Chi-square test results from cross tabulation on midterm and endline survey. 


\section{Hgrizons}

After about six months, an infant's nutritional needs are no longer fully satisfied by breast milk alone. NDP providers counseled all mothers, regardless of knowledge of HIV status, to begin gradually introducing appropriate complementary foods while continuing to breastfeed. Table 10 below indicates that this information appears to be successfully reaching mothers of older infants interviewed in the community by showing women's knowledge of foods for enriching their infants' diet.

Table 10 Knowledge of foods that can be used to enrich infants' diet among community mothers of infants age 6 to less than 12 months

\begin{tabular}{lccc}
\hline & $\begin{array}{c}\text { Baseline } \\
\mathbf{n}=\mathbf{8 8} \\
\mathbf{\%}\end{array}$ & $\begin{array}{c}\text { Midterm } \\
\mathbf{n = 7 2} \\
\mathbf{\%}\end{array}$ & $\begin{array}{c}\text { Endline } \\
\mathbf{n = 5 1} \\
\mathbf{\%}\end{array}$ \\
\hline Groundnuts & 70.5 & 73.6 & 80.4 \\
Kapenta (fish) & 8.0 & 13.9 & 11.8 \\
Soup & 3.4 & 13.9 & 17.6 \\
Milk & 20.5 & 34.7 & 33.3 \\
Sugar & 44.9 & 55.6 & 52.9 \\
Salt & 22.0 & 52.8 & 49.0 \\
Cooking oil & 47.7 & 44.4 & 43.1 \\
Fruit & 3.4 & 4.2 & 11.8 \\
Egg & NA & 26.4 & 39.2 \\
Soya & NA & 26.4 & 27.5 \\
Other & 27.3 & 31.9 & 27.5
\end{tabular}

For HIV-positive mothers, MTCT risks outweigh breast milk's benefits after six months. Despite improved infant feeding knowledge, few mothers interviewed at clinics had chosen to completely discontinue breastfeeding at six months - in fact, almost all mothers of infants up to 12 months old were currently breastfeeding when interviewed. HIV status awareness appears not to have affected the practice of continuing to give breast milk beyond six months, most likely for economic reasons and to avoid the stigma associated with not breastfeeding.

"About feeding the baby, they said I should breast him because I can't be buying the milk daily."

HIV-positive mother, 22 years, first interview, three weeks postpartum 


\section{VCT Awareness Increased But Uptake Remains Low}

Awareness of the confidential, free VCT services being offered at the health centers increased significantly among all community respondents, from 45 percent of all respondents at baseline to 79 percent at endline. In particular, among mothers interviewed in the community, awareness increased from 55.5 percent at baseline to 88.4 percent at endline.

Prior to the intervention, the majority of respondents were aware that an HIV test could be obtained at the main hospital, but only a few cited the NGO site (Hope Humana). After the start of the intervention, including the introduction of VCT services at Lubuto, community members' ability to name the places at which VCT services were available increased, particularly among mothers of infants less than six months old, although awareness of the NGO site remained low.

Table 11 Knowledge of VCT sources

\begin{tabular}{lccc}
\hline & $\begin{array}{c}\text { Baseline } \\
\%\end{array}$ & $\begin{array}{c}\text { Midterm } \\
\%\end{array}$ & $\begin{array}{c}\text { Endline } \\
\%\end{array}$ \\
\hline $\begin{array}{l}\text { Community mothers of infants } \\
\text { less than 6 mos. old }\end{array}$ & $\mathbf{n = 2 0 9}$ & $\mathbf{n = 3 1 9}$ & $\mathbf{n}=\mathbf{3 5 4}$ \\
Ndola Central Hospital & 71.7 & 87.1 & 92.4 \\
Lubuto Clinic & $\mathrm{N} / \mathrm{A}$ & 57.7 & 63.0 \\
Hope Humana & 2.7 & 3.8 & 9.0 \\
Adult survey females & $\mathbf{n}=\mathbf{3 8 5}$ & $\mathbf{n}=\mathbf{4 4 1}$ & $\mathbf{n}=\mathbf{3 9 6}$ \\
Ndola Central Hospital & 73.6 & 83.2 & 88.9 \\
Lubuto Clinic & $\mathrm{N} / \mathrm{A}$ & 38.1 & 47.6 \\
Hope Humana & 2.3 & 3.2 & 7.3 \\
Community survey males & $\mathbf{n}=\mathbf{2 5 1}$ & $\mathbf{n}=\mathbf{2 3 2}$ & $\mathbf{n}=\mathbf{2 3 1}$ \\
Ndola Central Hospital & 77.0 & 85.8 & 92.2 \\
Lubuto Clinic & N/A & 25 & 45 \\
Hope Humana & 3.2 & 3.9 & 15.7
\end{tabular}




\section{Hgrizons}

Meanwhile, community respondents reporting that they had ever been tested increased, indicated a slow increase in the continued uptake of services. Overall, utilization remained low, although it was higher for mothers in the community than for other men and women surveyed, who were more likely to have been encouraged to use the VCT service while attending ANC visits. These findings suggest that although community members are increasingly aware of the VCT services, they continue to regard VCT as a source of stress and choose not to use services. This is confirmed by the lack of change in the number of mothers interviewed in the community who agreed with the statement "being tested for HIV reduces worries," as shown in Table 12 below.

\section{Figure 3 Ever taken HIV test, community respondents}

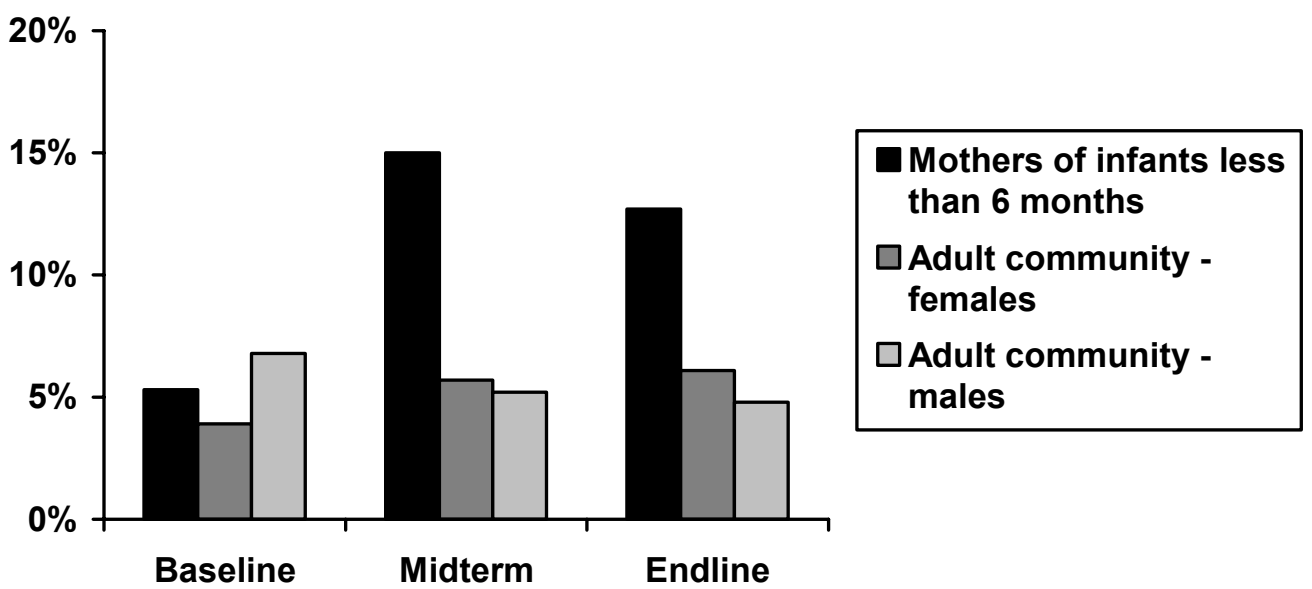

Table 12 Responses to "being tested for HIV reduces worries," community mothers of infants less than 6 mos. old

\begin{tabular}{lccc}
\hline & $\begin{array}{c}\text { Baseline } \\
\mathbf{n = 2 0 9} \\
\mathbf{\%}\end{array}$ & $\begin{array}{c}\text { Midterm } \\
\mathbf{n = 3 1 9} \\
\mathbf{\%}\end{array}$ & $\begin{array}{c}\text { Endline } \\
\mathbf{n = 3 5 4} \\
\mathbf{\%}\end{array}$ \\
\hline Completely agree & 29.8 & 28.8 & 29.1 \\
Somewhat agree & 10.1 & 20.4 & 15.8 \\
Completely disagree & 60.1 & 50.8 & 55.1
\end{tabular}




\section{Sexual Risk Reduction Needs Further Emphasis in the Community}

Prevention of new HIV infection remains a vital component of the MTCT package, which included risk-reduction counseling and condom promotion for all clinic attendees. Little change in reported risk perception was noted among all groups between baseline and endline. Approximately half of all mothers surveyed in the community reported that they felt at risk of HIV infection, most often due to a lack of trust in the sexual behavior of their partner.

"There is nothing you can do because he is refusing to use condoms."

Untested mother, 23 years, second interview, four months postpartum

"We don't talk about it [condoms], not even using it."

Untested mother, 27 years, third interview, three months postpartum
"I am so worried, especially about HIV, because as an individual I can keep myself from having other partners, but my friend [husband] can't keep himself..."

Untested mother, 31 years, first interview, four days postpartum

"You can look after yourself, but you don't know your partner's movements. That's the problem." Untested mother, 22 years, first interview, six days postpartum
Among all mothers interviewed in the community, condom use at last sex with regular partners was low and remained stable at approximately 13 percent for all survey rounds. Data from the community surveys suggest that while women are reducing their number of sexual partners, no significant change was observed among men. Among mothers, there was a significant increase in those reporting having one sexual partner ( 88.5 to 96.9 percent, $\mathrm{p}<0.05$ ), while among men, the increase was not significant (56.9 to 62.4 percent).

Table 13 Reported number of sexual partners, community surveys

\begin{tabular}{|c|c|c|c|c|c|c|}
\hline \multirow[t]{2}{*}{ Number of partners } & \multicolumn{3}{|c|}{ Mothers } & \multicolumn{3}{|c|}{ Men } \\
\hline & $\begin{array}{c}\text { Baseline } \\
\mathrm{n}=209 \\
\%\end{array}$ & $\begin{array}{c}\text { Midterm } \\
\mathrm{n}=314 \\
\%\end{array}$ & $\begin{array}{c}\text { Endline } \\
\text { n= } 354 \\
\%\end{array}$ & $\begin{array}{c}\text { Baseline } \\
\mathrm{n}=251 \\
\%\end{array}$ & $\begin{array}{c}\text { Midterm } \\
\text { n = } 232 \\
\%\end{array}$ & $\begin{array}{c}\text { Endline } \\
\mathrm{n}=231 \\
\%\end{array}$ \\
\hline None & 2.9 & 1.6 & 1.4 & 17.2 & 17.0 & 19.5 \\
\hline 1 & 88.5 & 95.0 & 96.9 & 56.9 & 66.5 & 62.4 \\
\hline 2 & 7.2 & 2.8 & 1.1 & 12.5 & 11.0 & 10.2 \\
\hline 3 or more & 1.4 & 0.6 & 0.6 & 13.3 & 5.5 & 7.8 \\
\hline
\end{tabular}




\section{Communication and Disclosure Improved But Remain Limited}

HIV risk reduction communication remains limited although improvements were observed (see Table 14 below). Among mothers interviewed in the community, there were significant increases in those reporting that they had ever discussed HIV risks with anyone and specifically with their partner. These changes among women who were exposed to the intervention stand in marked contrast to the trend among adult women in the community in general, among whom no change was observed. Meanwhile, among men, although the number reportedly discussing HIV risks with anyone declined significantly, those reporting that they had discussed HIV risks specifically with their partners increased significantly.
"I just sit because, if you talk about it a lot, he might think that you are the one who is promiscuous and you would bring the HIV." Untested mother, 32 years, second interview, four months postpartum

"When we are seated with my husband and children we teach each other."

HIV-negative mother, 37 years, first interview, ten days postpartum

"He knows, but even if you talk about it, he doesn't answer."

Untested mother, 24 years, first interview, one day postpartum

Table 14 Discussion of HIV risks, community surveys

\begin{tabular}{lcccccc}
\hline Respondents & \multicolumn{2}{c}{$\begin{array}{c}\text { Discussed HIV risks } \\
\text { with anyone }\end{array}$} & \multicolumn{3}{c}{$\begin{array}{c}\text { Discussed HIV risks } \\
\text { with partner }\end{array}$} \\
& $\begin{array}{c}\text { Baseline } \\
\%\end{array}$ & $\begin{array}{c}\text { Midterm } \\
\%\end{array}$ & $\begin{array}{c}\text { Endline } \\
\%\end{array}$ & $\begin{array}{c}\text { Baseline } \\
\%\end{array}$ & $\begin{array}{c}\text { Midterm } \\
\%\end{array}$ & $\begin{array}{c}\text { Endline } \\
\%\end{array}$ \\
\hline $\begin{array}{l}\text { Community survey of } \\
\text { mothers with infants } \\
\text { less than 6 mos. old }\end{array}$ & 55.0 & 56.7 & 64.4 & 62.1 & 60.2 & 74.9 \\
$\begin{array}{l}\text { Community survey of } \\
\text { adult women }\end{array}$ & 51.9 & 45.8 & 51.3 & 45.4 & 52.0 & 60.1 \\
$\begin{array}{l}\text { Community survey of } \\
\text { adult men }\end{array}$ & 61.9 & 57.6 & 51.7 & 40.0 & 43.6 & 62.0
\end{tabular}


"[My husband] didn't say

anything, he just said ok."

HIV-positive mother, 26 years, first interview, four weeks postpartum
Although HIV status disclosure was high among those who tested before the intervention, less than two thirds of females who had disclosed reported that they had disclosed to their spouse. Among mothers interviewed in the community who had disclosed their status to anyone, disclosure to spouse increased from $4 / 10$ at baseline to 89.5 percent $(34 / 38)$ at midterm, and 86.5 percent $(32 / 37)$ at endline $(\mathrm{p}<0.05$, Fisher's Exact Test)
The proportion of women reporting that their partner had been tested for HIV rose from 6.8 percent at baseline to 41.7 percent at midterm and 46.5 percent at endline. However, an increasingly large minority of untested males and females reported that if tested, they would not disclose to their spouse, suggesting that fears of negative spousal reaction remain an important concern.
"He said no...Where can I contract HIV myself?" HIV-positive mother, 26 years, first interview, 11 days postpartum

\section{Routine ANC and Other MCH Services Need Additional Resources Too}

The intervention aimed to strengthen care during pregnancy, delivery, and the postnatal period by improving clinic infrastructure, providing supplies, and building health workers' numbers and capacity. However, survey data and clinic observations revealed that logistical obstacles hampered some of these goals.

Laboratory infrastructure improved, but shortages of syphilis and hemoglobin test kits resulted in little change in testing levels. Provision of nutritional supplements and practice of infection prevention procedures improved to some extent but were restricted by supply shortages, although this does not explain why low levels of providers were observed washing hands before conducting examinations, despite the availability of piped water. Since anemia and STIs are among the risk factors associated with increased risk of MTCT (WHO/UNAIDS/UNICEF 1998), the provision of the routine antenatal care package should always be considered part and parcel of a good MTCT program.

In accordance with the WHO approach mentioned earlier (see page 5 of the Introduction), the prevention of unintended pregnancy among HIV-infected women is an important component of any MTCT program. Family planning counseling, which should be provided as a vital part of the $\mathrm{MCH}$ package, appears to have improved under the NDP. Among mothers of infants less than six months old interviewed in the community, use of a modern method of contraception increased from 4.8 percent at baseline to 36.7 percent and 51.7 percent at midterm and endline, respectively. Researchers observed similar patterns in condom use: from 0.5 percent to 4.4 percent to 14.1 
percent. However, these very low baseline figures may have been affected by different skip patterns between the baseline and subsequent questionnaires.

\section{Care and Support Links Remain Poor}

Community links are essential to promote services and provide follow-up support for mothers after leaving the clinic. The project aimed to emphasize the development of a comprehensive referrals network between medical facilities and CBOs/NGOs to meet the care and support needs of PLHA, as shown in Figure 4.

Figure 4 Referrals network

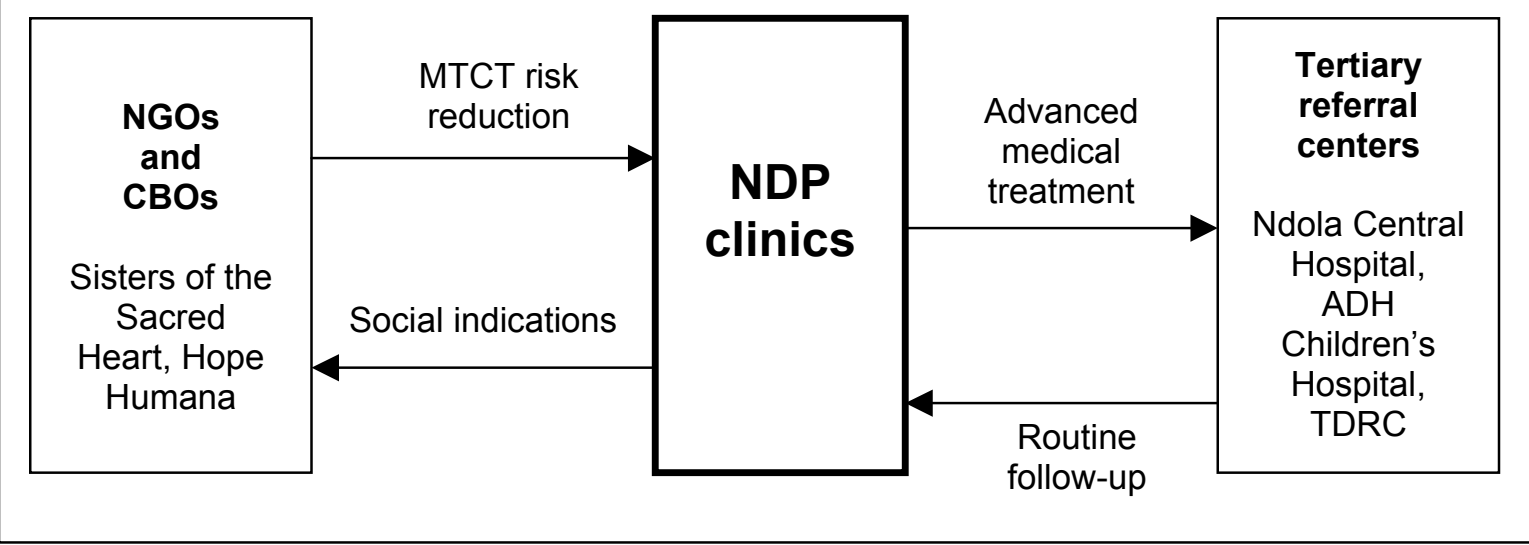

Referral slips were issued to each organization to track the number of referrals made and received. Table 15 below shows that during the period January to December 2001, a total of 9,087 referral slips were issued to the six NDP clinics, and 8,115 referrals were made, thus using 89.3 percent of the slips supplied. Referral tracing with the recipient organizations recovered records of 4,623 (57 percent) of these clients, implying that they had reached the sites to which they had been referred.

However, observations indicate that referrals remain limited to major hospitals for medical indications only, and not to CBOs/NGOs to meet care and support needs. Data collected up to August 2001 (see Appendix) indicate that referrals were going only in one direction, from the NGOs to the clinics, and from the clinics to the tertiary referral centers. Referrals in the other direction - from the medical centers to the NGOs to meet the care and support needs of PLHA- do not appear to be taking place. 
Food remains the most urgently identified need of PLHA, according to 76.4 percent of mothers interviewed in the community at baseline and 93.5 percent at endline.

Increasing collaboration between clinics and CBOs is required to provide continuity of care, ongoing information, and support structures for PLHA.

Table 15 Referral slip data January to December 2001

$\begin{array}{llr}\begin{array}{c}\text { Slips supplied } \\ \text { to referring site }\end{array} & \text { Referrals made } & \begin{array}{r}\text { Slips recovered } \\ \text { at recipient sites }\end{array}\end{array}$

\begin{tabular}{lrcc}
\hline Kabushi & 1,500 & 1,334 & 851 \\
Twapia & 1,850 & 1,709 & 964 \\
Mushili & 1,558 & 1,402 & 815 \\
Lubuto & 1,950 & 1,774 & 1,024 \\
Kaloko & 600 & 544 & 297 \\
Masala & 1,629 & 1,352 & 672 \\
Total & $\mathbf{9 , 0 8 7}$ & $\mathbf{8 , 1 1 5}$ & $\mathbf{4 , 6 2 3}$ \\
Percent & & $\mathbf{8 9 . 3 \%}$ & $\mathbf{5 7 \%}$ \\
& & & $\mathbf{( 4 , 6 2 3 / 8 , 1 1 5 )}$
\end{tabular}




\section{Hgrizons}

\section{Discussion and Conclusions}

The purpose of the NDP was to examine the feasibility of counseling interventions for the prevention of MTCT (VCT and IFC) in a community without access to short course ARVs or safe breast milk substitutes. The interventions aimed to enable women to make and implement informed decisions to protect themselves, their infants, and their spouses from HIV. The results show that integration of VCT and IFC into clinic- and community-based MCH services was indeed feasible, by means of successful collaborative efforts and local ownership throughout the project cycle.

Project implementers overcame supply-side obstacles to meet the logistical requirements of VCT service delivery in this setting, but faced low demand for service uptake, even when awareness of the availability of testing increased. Although there was some positive impact in terms of disclosure of test results to partners and uptake of testing by spouses, it is possible that the limited uptake of VCT overall may be due to stigma or a lack of tangible incentives to use the services (e.g., no ARVs or breast milk substitute).

The study showed that increasing mothers' knowledge that HIV may be transmitted through breast milk did not erode good breastfeeding practices. Education stressing the overall benefits of breast milk appears to have enabled mothers to evaluate relative risks and benefits and still make the healthy choice of exclusive breastfeeding. Building on a history of breastfeeding interventions in Ndola, including community-based motivators and community mobilization efforts, the NDP interventions strengthened exclusive breastfeeding rates yet further. Continued training of clinicand community-based health workers helped to sustain the levels of EBR that were already high. For mothers of older infants, knowledge about enriching complementary foods appears to be improving.

Evidence from Ndola suggests that women remain at risk of HIV infection during the perinatal period due to their partners' behavior. The responses of mothers in the clinics and community appear to indicate that they had tried to reduce sexual risks, but that options under their own control may have been limited due to gender-related power imbalances within their relationships. It is possible that the absence of significant preventive behavior change is associated with cultural taboos preventing women from discussing such sensitive issues as sexual behavior and serostatus with their spouse. Further research is required to explore ways of reaching men with risk-reduction information, such as couple counseling and community-wide education campaigns.

Problems inherent in the existing health care system, including erratic basic routine supplies, staff shortages, and low staff morale, hampered the provision of a comprehensive MCH package. NDP program inputs were limited to the new program components (VCT and IFC). Continued investments in both human and physical resources are necessary to continue to provide communities with the staff and infrastructure requirements of routine and enhanced services. MTCT risk-reduction programs must strengthen routine $\mathrm{MCH}$ care as an integral component of providing enhanced services for selected elements. Increasing collaboration between the clinics and CBOs is required to build a comprehensive referrals network that will provide information and ongoing support structures for PLHA. 
The study had three points of measurement to track the effects of the interventions in real-life settings with high staff turnover and other practical constraints. The trend in most indicators shows that the greatest changes took place within the period immediately following the introduction of the intervention, reaching a plateau of little further change by endline. It is hypothesized that impact is greatest during the initial stages of the intervention due to the initial burst of energy from staff immediately after training, which gradually declines over time. This indicates a need for pre-service, in-service, and refresher training to boost staff knowledge and morale and address the issue of high staff turnover.

Without a comparison area, the NDP findings cannot strictly be attributed to the intervention alone. However, the study demonstrated encouraging results in improving the capacity of mothers to make informed decisions favoring their own health and the health of their infant. The interventions succeeded in raising awareness about HIV and MTCT and in setting up VCT and IFC services as part of the existing MCH services, as well as good referral links in the community. With or without ARVs, counseling interventions will remain crucial components for the success of any MTCT reduction program.

\section{Program Modifications}

As data emerged from the Ndola Demonstration Project, the program was modified to recognize lessons learned. A series of strategic planning sessions with district health management teams and consultants, focused on assessing problematic areas and strengthening the intervention. These modifications were intended to address factors contributing to the low uptake of VCT, including the provision of $\mathrm{ARVs}$, improving the quality of infant feeding counseling, and increasing community awareness of PMCT services in order to increase demand. These program modifications were included in the scale up to other districts and were used by the Central Board of Health $(\mathrm{CBoH})$ to expand its National PMCT Plan.

\section{Policy and advocacy}

As the NDP scaled up to other districts, it became necessary to advocate for a collaborative strategic framework for PMCT expansion, with attendant guidelines. This framework ensures that the $\mathrm{CBoH}$ coordinates and takes a leading role in the implementation of PMCT activities.

Advocacy for routine counseling and voluntary testing has received substantial attention from the $\mathrm{CBoH}$ and Ministry of Health, and some sites are piloting this intervention. 


\section{Hgrizons}

\section{Antiretroviral drug intervention}

The $\mathrm{CBoH}$ and target districts phased in plans to introduce the antiretroviral drug nevirapine to reduce MTCT in June 2002. Steps were taken to develop protocols and advocate for adequate supplies of test kits and ARVs. Community leaders were sensitized, and health providers were trained to assess, counsel, and administer nevirapine to mother-baby pairs. District site coordinators were trained to track the mother-baby pairs to assure compliance and follow-up.

\section{Maternal and child health services}

Strengthening of ANC and PMCT services within the MCH system was essential to improve the quality of services along the continuum of care. The district health teams improved delivery strategies and coverage for PMCT services through an integrated approach that allowed a more complete package of ANC essential services; routine VCT; risk reduction policies for labor, delivery, and postpartum care; a prophylactic antiretroviral drug intervention; counseling and support for all mothers on infant feeding options; and improved referral links with the community. The district health teams set goals to expand the number of health providers trained in essential care and counseling.

\section{VCT and same-day test results}

Factors that contributed to low VCT uptake included stigma, lack of ARVs, inadequate community support for people testing positive for HIV, long wait time for results, and lack of community mobilization to support family decision making for $\mathrm{MCH}$ and VCT services. The district health management teams took steps to improve service delivery and counter disincentives to improve VCT uptake, including ensuring adequate supplies of test kits and ARVs. Specimen transport and logistics systems were strengthened. Health providers were trained in the rapid testing method, and $\mathrm{MCH}$ clinics implemented policies to provide same-day results and counseling to their clients. There is currently strong advocacy for training lay counselors in same-day testing to increase the overburdened counseling staff.

\section{PMCT training}

Current capacity building activities were designed to use existing local trainers for most activities to ensure that districts continue PMCT training using their own resources or funds donated by other organizations. Changes have been made in the basic PMCT curriculum for health providers to incorporate behavior change communication methodology so that providers can promote behavior change in individual clients. 


\section{VCT and infant feeding counseling}

Clinics in target districts decided to make VCT routine by instituting a policy that all ANC attendees should be counseled on the benefits of VCT. Counselors and health providers were trained to include VCT as an integral part of the ANC package. ANC women were provided with VCT information in large group sessions and through individual counseling. Women choosing to test received pre- and post-test counseling emphasizing prevention, family planning, and community support services for infant feeding and for PLHA. Partners were encouraged to attend the counseling sessions. Infant feeding counseling was also made routine so that all pregnant women in the ANC, labor and delivery, postpartum, and family planning clinics were counseled on infant feeding choices according to their HIV status.

\section{Community care and support systems}

The behavior change strategy for PMTCT was strengthened to target women of reproductive age, their partners, and youth. ANC clinics expanded youth corners for education and peer counseling and encouraged male involvement in VCT. Communities were sensitized on modes of prevention, PMCT, and safe infant feeding options. The links between clinics and community support systems were strengthened to provide follow-up support for mothers after leaving the clinic and to HIVpositive mothers for care and support community services. Collaborative relationships with community-based organizations in target districts were strengthened. Community service providers were trained through a modified curriculum to provide PMCT and infant feeding education and to motivate and mobilize community systems.

\section{Evaluation, documentation, and dissemination}

Program sites standardized their information systems for PMCT, VCT, and infant feeding counseling. District site coordinators were designated to provide quality checks on data collection. Data are now routinely used for decision making for program improvements. More regular follow up of counselors and motivators is facilitated by quarterly meetings to discuss their performance using district performance data on PMCT and VCT issues. 


\section{Hgrizons}

\section{References}

de Zoysa, Isabelle et al. 2002. "Strategic approaches to preventing HIV infections in infants: balancing priorities in different settings." Abstract ThOrD1431, XIV International AIDS Conference, Barcelona, Spain, 7-12 July.

Horizons Project. 2000. Assessing the capacity for community-based counseling and referral in the Ndola Demonstration Project. Nairobi: Population Council.

LINKAGES. 2001 "FAQ sheet: frequently asked questions on breastfeeding and HIV/AIDS." Washington: LINKAGES.

_. 2000. World linkages: Zambia country profile. Washington: LINKAGES.

Musonda, R.M. et al. 1999. "HIV-1 prevalence using antenatal clinic attenders versus the general population, Ndola, Zambia." Abstract 14ET 3-4, 11 th International Conference on AIDS and STDs in Africa, Lusaka, Zambia, 12-16 September.

NFNC/LINKAGES/SARA/USAID. 1999. "Ndola demonstration project to integrate infant feeding counseling and HIV voluntary testing into health care and community services: HIV and infant feeding." Formative research report. Lusaka: LINKAGES.

WHO/UNAIDS/UNICEF. 1998. HIV and Infant Feeding: A guide for health-care managers and supervisors. Geneva. WHO/FRH/NUT/CHD/98.2 UNAIDS/98.4 UNICEF/PD/NUT/(J)98-2.

Available at www.unaids.org/publications/documents/mtct/infantguide.html. 


\section{Additional Reading}

LINKAGES. 1999. Recommended Feeding and Dietary Practices to Improve Infant and Maternal Nutrition. Washington: LINKAGES.

Horizons Program. 2002. Ndola Demonstration Project: a midterm analysis of lessons learned. Nairobi: Population Council.

Muuyunda E. et al. 2002. "The effect of integrated Prevention of Mother-to-child Transmission services on HIV risk reduction among mothers in Ndola, Zambia." Abstract MoPeD 3576, XIV International Conference on AIDS, Barcelona, July 7-12, 2002.

Schenk, K. 2003. "Breastfeeding education helps PMTCT." AIDSLink 78. Available at http://www.globalhealth.org/publications/article.php3?id=914.

UNAIDS. 2002. HIV voluntary counseling and testing: a gateway to prevention and care [uses NDP as a case study]. Geneva: UNAIDS. 
Hgrizons

\section{Appendix A}

\section{Service Statistics}

ANC clients accepting testing, May 2000 - March 2002

\begin{tabular}{|c|c|c|c|c|c|c|c|}
\hline \multirow[b]{2}{*}{$\begin{array}{l}\text { Survey } \\
\text { period }\end{array}$} & \multirow[b]{2}{*}{ Month } & \multicolumn{3}{|c|}{ Rates by month } & \multicolumn{3}{|c|}{$\begin{array}{l}\text { Rates for survey period } \\
\text { (monthly average) }\end{array}$} \\
\hline & & $\begin{array}{l}\text { ANC } \\
\text { clients } \\
\text { tested }\end{array}$ & $\begin{array}{l}\text { New } \\
\text { ANC } \\
\text { clients }\end{array}$ & $\begin{array}{l}\% \text { ANC } \\
\text { clients } \\
\text { tested }\end{array}$ & $\begin{array}{l}\text { ANC } \\
\text { clients } \\
\text { tested }\end{array}$ & $\begin{array}{l}\text { New } \\
\text { ANC } \\
\text { clients }\end{array}$ & $\begin{array}{l}\% \text { ANC } \\
\text { clients } \\
\text { tested }\end{array}$ \\
\hline & May-00 & 52 & 501 & 10.4 & & & \\
\hline & Jun-00 & 101 & 560 & 18.0 & & & \\
\hline & Jul-00 & 111 & 543 & 20.4 & & & \\
\hline & Aug-00 & 154 & 555 & 27.7 & & & \\
\hline & Sep-00 & 77 & 507 & 15.2 & & & \\
\hline & Oct-00 & 45 & 608 & 7.4 & & & \\
\hline & Nov-00 & 44 & 649 & 6.8 & & & \\
\hline & Dec-00 & 96 & 396 & 24.2 & & & \\
\hline & Jan-01 & 67 & 616 & 10.9 & & & \\
\hline & Feb-01 & 65 & 582 & 11.2 & & & \\
\hline & Mar-01 & 119 & 617 & 19.3 & & & \\
\hline \multirow[t]{11}{*}{ Midterm } & Apr-01 & 53 & 507 & 10.5 & 82 & 553 & 14.8 \\
\hline & May-01 & 49 & 564 & 8.7 & & & \\
\hline & Jun-01 & 64 & 485 & 13.2 & & & \\
\hline & Jul-01 & 63 & 556 & 11.3 & & & \\
\hline & Aug-01 & 56 & 551 & 10.2 & & & \\
\hline & Sep-01 & 25 & 605 & 4.1 & & & \\
\hline & Oct-01 & 25 & 573 & 4.4 & & & \\
\hline & Nov-01 & 25 & 522 & 4.8 & & & \\
\hline & Dec-01 & 17 & 528 & 3.2 & & & \\
\hline & Jan-02 & 34 & 680 & 5.0 & & & \\
\hline & Feb-02 & 26 & 603 & 4.3 & & & \\
\hline Endline & Mar-02 & 54 & 642 & 8.4 & 40 & 574 & 6.9 \\
\hline
\end{tabular}




\section{Appendix B}

\section{Referrals Data}

By August 2001, the six DHMT clinics had issued 650 referral slips, of which 373 were to Ndola Central Hospital (NCH) and 275 to the Arthur Davison Hospital (ADH) for children. Records have been found for 276 (74 percent) of the $\mathrm{NCH}$ referrals and 217 (79 percent) of the ADH referrals, indicating that the patients arrived where they were referred. None of the referrals so far went to CBOs.

The Sisters of the Sacred Heart has used 100 referral slips given by NDP. Of these, 79 could be traced as follows: 52 to the home-based care program of NCH, 19 to Hospice, 2 to ADH, 2 to the $\mathrm{TB}$ clinic at $\mathrm{NCH}$, and 4 to the $\mathrm{NCH}$ casualty department. Hope Humana received 50 referral slips in January 2001 and by August 2001 had used 29, 15 of which were traced to NCH, 8 to Zambia Flying Doctors Service, and 1 to the Railway clinic. 


\section{Hgrizons}

Appendix C

\section{Research Assistants During the Baseline, Midterm, and Endline Surveys}

\author{
Sylvia N. Akapelwa \\ Maria S. Daka Banda \\ Emmanuel M Buya \\ Regina M. Bwalya \\ Theresa C. Bwalya \\ Rosinah Mubanga Chansa \\ Esther K. Cheuka \\ Marureen Kapumpu Chikwa \\ Veronica Tembo Chilekwa \\ Rovert K. Chinyanta \\ Andrew Chilambe Chipapa \\ Cleopatra Himabilo Chisumpa \\ Doreen S. Chiyesu \\ Mary Mulenga Kaboyi \\ Rosaria Kabongola Kahunga \\ Annie Makalio Kaira \\ Chad Kalobwe \\ Roseline Netsail Kapapa \\ Mary Goma Kaponda \\ Mary W. Kaponda \\ Milner N. Kasempa \\ Regina Kasompe \\ Esnelly A. Kasongo \\ Catherine Shimpano Katongo \\ Hildah Kaunda \\ Agness Musonda Lungu \\ Justina Sitali Lungu \\ Beatrice M. Lupunga \\ Lynett H. S. Maambo \\ Ronah Maambo \\ Queen Namukoko Manjimela
}

\author{
Likando Sitali Masinge \\ Fingani Thomson Mbeba \\ Carol Kunda Mbewe \\ Nelly Nchimunya Mizinga \\ Queen Mwansa Moyowanyambe \\ Stephanie B. Mpabalwani \\ Mary M. Mufaya \\ Joyce Mateo Mulenga \\ Marjorie Mwandu Mulenga \\ Christine Nawa Muyunda \\ Mary Y. Mwamba \\ Joyce K. Mwami \\ Marjory Sydney Mwandu \\ Mavis M. Mwiinga \\ Maureen Mzumara \\ Pamela Kelembe Namwanza \\ Poso Ngalande \\ Dorothy Kabuswe Nkonde \\ Elizabeth M. Nonde \\ Tina Nyirenda \\ Mwansa Mulenga M. Regina \\ Esther K. Sakala \\ Rhodah Phiri Sakala \\ Yvonne Shuko \\ Martha M. Siamuzwe \\ Luck A. Silengo \\ Mirriam Soko \\ Annie S. Syabeene \\ Evelyn Chewe Talanki \\ Lynn M. Tamba \\ Agness Lemba Tembo
}




\section{Hgrizons priz}

Horizons is a global operations research program designed to:

- Identify and test potential strategies to improve HIVIAIDS prevention, care, and support programs and service delivery.

- Disseminate best practices and utilize findings with a view toward scaling up successful interventions.

\section{(1) Population Council}

Horizons is implemented by the Population Council in collaboration with

- International Center for Research on Women (ICRW)

- International HIVIAIDS Alliance

- Program for Appropriate Technology in Health (PATH)

- Tulane University

- Family Health International (FHI)

- Johns Hopkins University

For more information, please contact:

Horizons Program, Communications Unit 4301 Connecticut Avenue, NW Suite 280 Washington, DC 20008 USA

Tel: 202-237-9400

Fax: 202-237-8410

Email: horizons@pcdc.org www.popcouncil.org/horizons 